\title{
Detection and attribution analysis of annual mean temperature changes in China
}

\author{
Ying $\mathrm{Xu}^{1, *}$, Xuejie $\mathrm{Gao}^{2}$, Ying $\mathrm{Shi}^{1}$, Zhou Botao ${ }^{1}$ \\ ${ }^{1}$ National Climate Center, China Meteorological Administration, 100081 Beijing, China \\ ${ }^{2}$ Climate Change Research Center, Institute of Atmospheric Physics, Chinese Academy of Sciences, 100029 Beijing, China
}

\begin{abstract}
Using an optimal fingerprinting method and the Coupled Model Intercomparison Project Phase 5 (CMIP5) multi-model simulations, we attempted to quantify the human contribution to the observed annual mean temperature change that occurred over China between 1961 and 2005. Results indicate that the combined effects of greenhouse gases and sulfate aerosol forcing are clearly detectable in the observed annual mean temperature change. Effects of anthropogenic and natural forcings are separately detectable, and the climate response to greenhouse gas forcing can be identified clearly and robustly. Our results also show that only when anthropogenic forcing is involved can the observed changes in China's mean temperature from 1961 to 2005 be explained.
\end{abstract}

KEY WORDS: Detection and attribution $\cdot$ Climate change $\cdot$ CMIP5 $\cdot$ Models

\section{INTRODUCTION}

The Fifth Assessment Report (AR5) of the Intergovernmental Panel on Climate Change (IPCC 2013) illustrates the latest advances in climate change research since the publication of AR4 (IPCC 2007). It assesses the science of climate change, impacts, adaptation and mitigation in the present and future at both regional and global scales. Understanding the causes of observed changes in climate is an important focus of this assessment, since this provides not only an explanation for the observed changes, but also confidence in model performance and projection. AR5 states that 'Human influence has been detected in warming of the atmosphere and the ocean, in changes in the global water cycle, in reductions in snow and ice, in global mean sea level rise, and in changes in some climate extremes' (IPCC 2013, p. 17).

Detection and attribution of climate change in terms of the relative contribution of anthropogenic and natural factors is a hot topic, and one of the key issues in the global climate change debate. It pro-

${ }^{*}$ Corresponding author: xuying@cma.gov.cn vides an important scientific basis to answer the question of whether, and to what extent, human activities have influenced climate change. The detection and attribution of climate change was initially conducted on the annual mean temperature at a global scale. Now, it extends to other components of the climate system such as precipitation, sea level pressure, climate extremes, and other variables that are more impact-relevant and occur on various space-time scales (IPCC 2013).

The use of climate model simulations is a very important approach in climate change detection and attribution analyses, as reviewed by Hegerl \& Zwiers (2011). The recently completed Coupled Model Intercomparison Project Phase 5 (CMIP5) provides historical climate simulations under the combined effect of external forcings as well as individual forcings, with a compilation of over 50 models from different modeling centers around the world (Taylor et al. 2012). These simulations provide an important foundation for the detection and attribution of climate change as it enables climatic responses to various forcings to be assessed. Using the Hadley Centre new Global Envi-

() The authors 2015. Open Access under Creative Commons by Attribution Licence. Use, distribution and reproduction are unrestricted. Authors and original publication must be credited. 
ronmental Model 2 Earth System (HadGEM2-ES) model simulations, Stott \& Jones (2012) detected the effect of greenhouse gas forcing on the global mean temperature. Gareth et al. (2013) conducted a more comprehensive analysis by using simulations from multiple models, trying to attribute observed historical near-surface temperatures to anthropogenic and natural external forcings. The results indicated that anthropogenic emissions of greenhouse gases are the dominate causes of the observed global warming that has occurred since the mid-20th century. Of the estimated observed warming trend of $\sim 0.6 \mathrm{~K}$, between 0.6 and $1.2 \mathrm{~K}$ can be attributed to greenhouse gases, balanced by a counteracting cooling of between 0 and $-0.5 \mathrm{~K}$ from other anthropogenic forcings such as anthropogenic aerosols.

While it is important to understand the causes of warming at a global scale, the interests and concerns of policy makers are aimed more towards regional and even local scales. Thus, considerable efforts have been made towards attributing observed changes at regional scales (e.g. Zwiers \& Zhang 2003, Zhang et al. 2006, Hegerl et al. 2007, Stott et al. 2010). As in other parts of the world, significant warming has been observed over China in the last several decades (e.g. Zhai \& Pan 2003, Tang \& Ren 2005, Qian et al. 2011, Ren \& Zhou 2014).

A limited number of studies have been conducted using the optimal fingerprinting method, to understand the causes of these observed temperature changes. Zhou \& Yu (2006) analyzed temperature changes in the 20th century, simulated by 19 models from CMIP3. They found a high correlation between mean temperature in China and model simulated responses under the combined effects of anthropogenic and natural forcing, indicating an influence from external forcings. External forcing explained $32.5 \%$ of the annual mean temperature change in the 20th century over China, while internal variability was as high as $67.5 \%$. This suggests that attribution of the changes at a regional scale is much more complex compared to that at a global scale. Using the optimal fingerprinting method, Zhang et al. (2006) quantitatively compared temperature changes in the observations and responses to external forcings simulated by 2 models over different regions, including China. They detected the effect of anthropogenic forcing from greenhouse gases and sulfate aerosols in the annual mean temperature over China. Using an optimal detection method, Wen et al. (2013) compared spatio-temporal patterns of 4 extreme indices (namely annual maxima of daily maximum and daily minimum temperatures and annual minima of daily maximum and daily minimum temperatures) with those observed and simulated by the Canadian Earth System Model 2 (CanESM2) over China between 1961 and 2007. They established a clear connection between human emission of greenhouse gases and extreme temperature changes in China. More recently, Sun et al. (2014) compared the observed summer temperature changes with those simulated by CMIP5 models, with a focus on the 2013 heat event in eastern China, and found contributions from anthropogenic influences. Zhou et al. (2014) reported that both anthropogenic influences and the internal variability of the Pacific decadal oscillation/interdecadal Pacific oscillation (PDO/IPO) contributed to the heat event in eastern China in 2013. Other attribution studies include the applications of a single global model, the Bergen Climate Model (BCM; Wang et al. 2013) and a single regional model, the Regional Climate Model version 4 (RegCM4; Zhang et al. 2015) to investigate the possible human influences on the rainfall patterns observed in China over the last several decades.

The objective of the study was to try to further understand the surface temperature response over China to external forcings during the period of 19612005 based on the CMIP5 multi-model ensemble. We focused on annual mean temperature only in the present period.

\section{DATA}

\subsection{Observational data}

The observational dataset employed in this study is an updated version of the gridded daily scale dataset, CN05.1, developed by Wu \& Gao (2013). The difference between the updated dataset and the original CN05.1 is that station data employed in the interpolation has been homogeneously adjusted by China's National Meteorological Information Center using RHtest of Wang et al. (2007). This homogenization resulted in some differences between the 2 versions, similar to that found by Li et al. (2015) using a different method, Multiple Analysis of Series for Homogenization (MASH).

CN05.1 is the further improvement of CN05 (Xu et al. 2009), but is based on interpolation from more station observations (760 for CN05 vs. 2416 for CN05.1), comprises more variables and has a higher spatial resolution $\left(0.25^{\circ}\right.$ latitude $\times 0.25^{\circ}$ longitude $)$. The dataset was constructed following the commonly used 'anomaly approach', in which a gridded clima- 
tology is first calculated, and then a gridded daily anomaly is added to the climatology to obtain the final dataset. The density of stations used in CN05.1 is quite high over eastern China, but not so high in the west where population density and urban establishments are much lower, in particular over the Tibetan Plateau. More detailed information concerning the data construction and comparison with other datasets can be found in Xu et al. (2009) and Wu \& Gao (2013). CN05 and the updated CN05.1 are becoming more popular models for validation analysis over the Chinese region (e.g. Gao et al. 2011, Wu et al. 2012, Guo \& Wang 2013, Sui et al. 2014).

\subsection{Model data}

A typical detection and attribution analysis requires the use of model simulations to estimate climate responses (or signals) to external forcing as well as to internal variability. For this purpose, we used 296 simulations from the 20 models participating in
CMIP5 under various external forcings (Table 1). These models produced different ensembles for the period from 1850-2005, including (1) 118 historical forcing runs that included both anthropogenic and natural external forcing (ALL); (2) 48 natural forcing runs that only contain changes in solar irradiance and volcanic activity (NAT); and individual forcing runs, including (3) 42 runs under greenhouse gases (GHG); (4) 33 runs under anthropogenic aerosol (AA); (5) 15 runs under land use change (LU); and (6) 40 anthropogenic runs (ANT) (see Table 1). Each ensemble from a model contained at least 3 member runs. Detailed information on forcing data can be found on the CMIP5 website (http://cmip-pcmdi.llnl. gov/cmip5/forcing.html). These models were also conducted using different years of pre-industrial control simulation (CTL): a total of $13008 \mathrm{yr}$ in the 20 models. Values of annual mean temperature were extracted from the monthly outputs of these simulations for the estimation of internal variability. All model data were bilinearly interpolated to the common $1^{\circ} \times 1^{\circ}$ grids.

Table 1. The 20 models included in the Coupled Model Intercomparison Project Phase 5 (CMIP5). Atm. Res: atmospheric model resolution (in no. of grid squares); ALL: includes anthropogenic and natural external forcings; NAT: only solar irradiance and volcanic activity; GHG: greenhouse gases; ANT: anthropogenic influences; LU: land use changes; AA: anthropogenic aerosols; (-) not included

\begin{tabular}{|c|c|c|c|c|c|c|c|c|}
\hline Models & Institution and country & $\begin{array}{l}\text { Atm. Res } \\
(\text { lon } \times \text { lat })\end{array}$ & $\overline{A L L}$ & NAT & mber & $\begin{array}{l}\text { of run } \\
\text { ANT }\end{array}$ & $\mathrm{LU}$ & $\mathrm{AA}$ \\
\hline BCC-CSM1-1 & $\begin{array}{l}\text { Beijing Climate Center, } \\
\text { China Meteorological Administration, China }\end{array}$ & $128 \times 64$ & 3 & - & - & - & - & - \\
\hline BCC-CSM1-1-m & $\begin{array}{l}\text { Beijing Climate Center, } \\
\text { China Meteorological Administration, China }\end{array}$ & $320 \times 160$ & 3 & - & - & - & - & - \\
\hline CCSM4 & National Center for Atmosphere Research, United States & $288 \times 192$ & 6 & 4 & 3 & - & - & - \\
\hline CESM1-CAM5 & National Center for Atmosphere Research, United States & $288 \times 192$ & 3 & - & - & - & - & - \\
\hline CNRM-CM5 & CNRM and CERFACS, France & $256 \times 128$ & 10 & 6 & 6 & 10 & - & - \\
\hline CSIRO-Mk3-6-0 & CSIRO and QCCCE, Australia & $192 \times 96$ & 10 & 5 & 5 & 5 & - & 5 \\
\hline CanESM2 & Canadian Centre for Climate Modeling and Analysis, Canada & $128 \times 64$ & 5 & 5 & 5 & - & 5 & 5 \\
\hline FGOALS-g2 & $\begin{array}{l}\text { Institute of Atmospheric Physics, Chinese Academy of Sciences } \\
\text { and Tsinghua University, China }\end{array}$ & $128 \times 60$ & 5 & - & - & - & - & - \\
\hline FIO-ESM & The First Institution of Oceanography, China & $128 \times 64$ & 3 & - & - & - & - & - \\
\hline GFDL-CM3 & NOAA Geophysical Fluid Dynamics Laboratory, United States & $144 \times 90$ & 5 & 3 & 3 & 3 & - & 3 \\
\hline GISS-E2-H(p1,p2,p3) & NASA, GISS (Goddard Institute for Space Studies), United States & $144 \times 90$ & $3 \times 5$ & 5 & 5 & 10 & 5 & 10 \\
\hline GISS-E2-R(p1,p2,p3) & NASA, GISS (Goddard Institute for Space Studies), United States & $144 \times 90$ & $3 \times 6$ & 10 & 5 & 10 & 5 & 10 \\
\hline HadGEM2-ES & MOHC (Met Office Hadley Centre), UK & $192 \times 145$ & 4 & 4 & 4 & - & - & - \\
\hline IPSL-CM5A-LR & Institute Pierre-Simon Laplace, France & $96 \times 96$ & 6 & 3 & 3 & 2 & - & - \\
\hline MIROC-ESM & NIES, JAMSTEC, Japan & $128 \times 64$ & 3 & 3 & 3 & - & - & - \\
\hline MIROC5 & AORI, NIES, JAMSTEC, Japan & $256 \times 128$ & 5 & - & - & - & - & - \\
\hline MPI-ESM-LR & Max Planck Institute for Meteorology, Germany & $192 \times 96$ & 3 & - & - & - & - & - \\
\hline MPI-ESM-MR & Max Planck Institute for Meteorology, Germany & $192 \times 96$ & 3 & - & - & - & - & - \\
\hline MRI-CGCM3 & Meteorological Research Institute, Japan & $320 \times 160$ & 5 & - & - & - & - & - \\
\hline NorESM1-M & Norwegian Climate Centre, Norway & $144 \times 96$ & 3 & - & - & - & - & - \\
\hline \multicolumn{9}{|l|}{ Sum } \\
\hline Models & & & 20 & 10 & 10) & 6 & 3 & 5 \\
\hline (runs) & & & $(118)$ & $(48)$ & $(42$ & $(40)$ & $(15)$ & $(33)$ \\
\hline
\end{tabular}




\section{METHODS AND DATA PROCESSING}

\subsection{Detection and attribution method}

Climate change detection is defined as the process of demonstrating that climate (or a system affected by climate) has changed in some defined statistical sense, without providing a reason for that change. Climate change attribution is defined as the process of evaluating the relative contributions of multiple causal factors to a change or event with an assignment of statistical confidence. In the context of IPCC, detection also occasionally refers to the discovery of an influence from external forcings, and thus is closely linked to attribution (IPCC 2013). Casual factors usually refer to external influences, which may be anthropogenic (e.g. greenhouse gases, aerosols, ozone precursors, land use) and/or natural (e.g. volcanic eruptions, solar cycle modulations).

Detection and attribution have 4 core elements: observations of climate indicators from which climate responses to external forcing might be detected; an estimate of external forcing; a quantitative physicallybased understanding of how external forcing might affect these climate indicators, usually based on climate model simulations; and an estimate of climate internal variability, also typically based on climate model simulations. Additionally, it is important that the key external forces are identified, that signals and noise are additive, and that the large-scale patterns of response are correctly simulated by climate models (Bindoff et al. 2013).

A typical detection and attribution analysis uses an optimal fingerprint method based on generalized multivariate linear regression (e.g. Allen \& Tett 1999, Allen \& Stott 2003). The optimal fingerprinting method assumes that the climate response to different forcings superimposes linearly, and that the forced response also superimposes linearly on unforced climate variability. Consequently, detection and attribution relies heavily on climate models.

The optimal fingerprint method assumes that signals are linearly additive. This was found to be the case even for a highly non-linear system (Allen \& Stott 2003). The linearity of the climate response to different forcings has been evaluated in numerous studies and found to work well, at least for the transient climate response. The larger equilibrium temperature responses to aerosol and greenhouse gas emissions do not necessarily combine linearly (Ming \& Ramaswamy 2009). However, as the changes we examined in this study were small relative to the equilibrium state, we would assume such non-linearity to have little impact on our analysis.

The optimal fingerprint method assumes the observations are the sum of expected changes (scaled signals) and internal variability (residual), expressed as following equation:

$$
y=\beta X+\varepsilon
$$

Here, the vector $\mathbf{y}$ is a filtered version of the observed temperature record. Matrix $\mathbf{X}$ represents model-simulated signal patterns consisting of 1 or 2 vectors (i.e. either the estimated ANT signal in our 1signal analysis or the estimated GHG and AA signals in our 2-signal analysis). Vector $\varepsilon$ represents natural (residual) variability that is not explained by the signals. The scaling factor $\boldsymbol{\beta}$, a vector of 1 or 2 elements, adjusts the signal amplitude so that the scaled signal best matches the observations.

We conducted a single-signal analysis involving only 1signal vector at a time. The detection of a signal would indicate the presence of response to a particular forcing (or combined forcings) in the observations. As the observations may be influenced by multiple forcing factors, regression models with multiple predictors provide a better fit. Therefore, we also conducted a 2-signal analysis in which $\mathbf{X}$ had 2 signal vectors. The use of a 2-signal analysis allows the separation of responses to different forcings, so a clearer attribution to individual forcing can be obtained.

\subsection{Data processing}

\subsubsection{Methods}

The detection analysis was conducted based on temperature evolution over both space and time. For both observations and model simulations, we computed a regional time series of annual mean temperature anomalies over 8 sub-regions of China using area weighting. These regions were defined according to administrative boundaries and societal and geographical conditions, and were used in China's National Assessment Report on Climate Change (CCNARCC 2007). The 8 sub-regions consisted of northeastern China (NEC: $39-54^{\circ} \mathrm{N}, 119-134^{\circ} \mathrm{E}$ ), north China (NC: $36-46^{\circ} \mathrm{N}, 111-119^{\circ} \mathrm{E}$ ), eastern China (EC: $27-36^{\circ} \mathrm{N}, 116-122^{\circ} \mathrm{E}$ ), central China (CC: $\left.27-36^{\circ} \mathrm{N}, 106-116^{\circ} \mathrm{E}\right)$, southern China (SC: $20-$ $27^{\circ} \mathrm{N}, 106-120^{\circ} \mathrm{E}$ ), southwestern China (SWC1: $27-$ $\left.36^{\circ} \mathrm{N}, 77-106^{\circ} \mathrm{E}_{\text {; }} \mathrm{SWC2}: 22-27^{\circ} \mathrm{N}, 98-106^{\circ} \mathrm{E}\right)$ and northwestern China (NWC: $36-46^{\circ} \mathrm{N}, 75-111^{\circ} \mathrm{E}$ ), as outlined in Fig. 1 by the red rectangles. 
Detection and attribution analysis must usually be conducted within relatively small dimensions, due to a lack of sample data for the estimation of noise covariance, or because the estimated noise covariance matrix is not 'full rank' if the dimension is too large. We used 2 approaches to obtain small dimensions from annual mean temperatures: (1) we used multi-year non-overlapping means to reduce the time dimension; and (2) we further reduced the dimension by projecting the space-time series onto leading empirical orthogonal functions (EOFs) of the model-simulated natural variability. The use of shorter time averages may provide a better chance to detect climate response to short-time period forcings such as volcanic activities. However, the use of shorter time averages also requires estimation of a larger covariance matrix, which results in larger estimation error with the limited data sample. According to Wen et al. (2013), if an analysis is conducted on different multi-year non-overlapping mean series, the detection results are not sensitive to the use of time averaging. For this reason, we based our results on the analysis of a $9 \mathrm{yr}$ mean series. The number of
EOFs retained was determined by a residual consistency check (Allen \& Tett 1999). Further details on the data processing are described in the next section.

\subsubsection{Observations and model data processing}

The original resolution of CN05.1 is $0.25^{\circ}$ latitude $\times$ $0.25^{\circ}$ longitude, and was re-grid to the $1^{\circ} \times 1^{\circ}$ grids in the present study using the interpolation method of conservative remapping in order to facilitate comparison with model simulations. Observed daily temperatures were averaged to obtain monthly values over China. Monthly anomalies relative to the base period of 1961-1990 were then computed for each grid. Finally, regional mean series were computed based on available grid values weighted by the grid box area for the 8 sub-regions. The 9 yr non-overlapping averages of regional annual series were used for subsequent detection and attribution analyses.

Due to the different spatial resolution of multimodel data, we re-grid all model data into the common $1^{\circ}$ latitude $\times 1^{\circ}$ longitude grid. Also, prior to

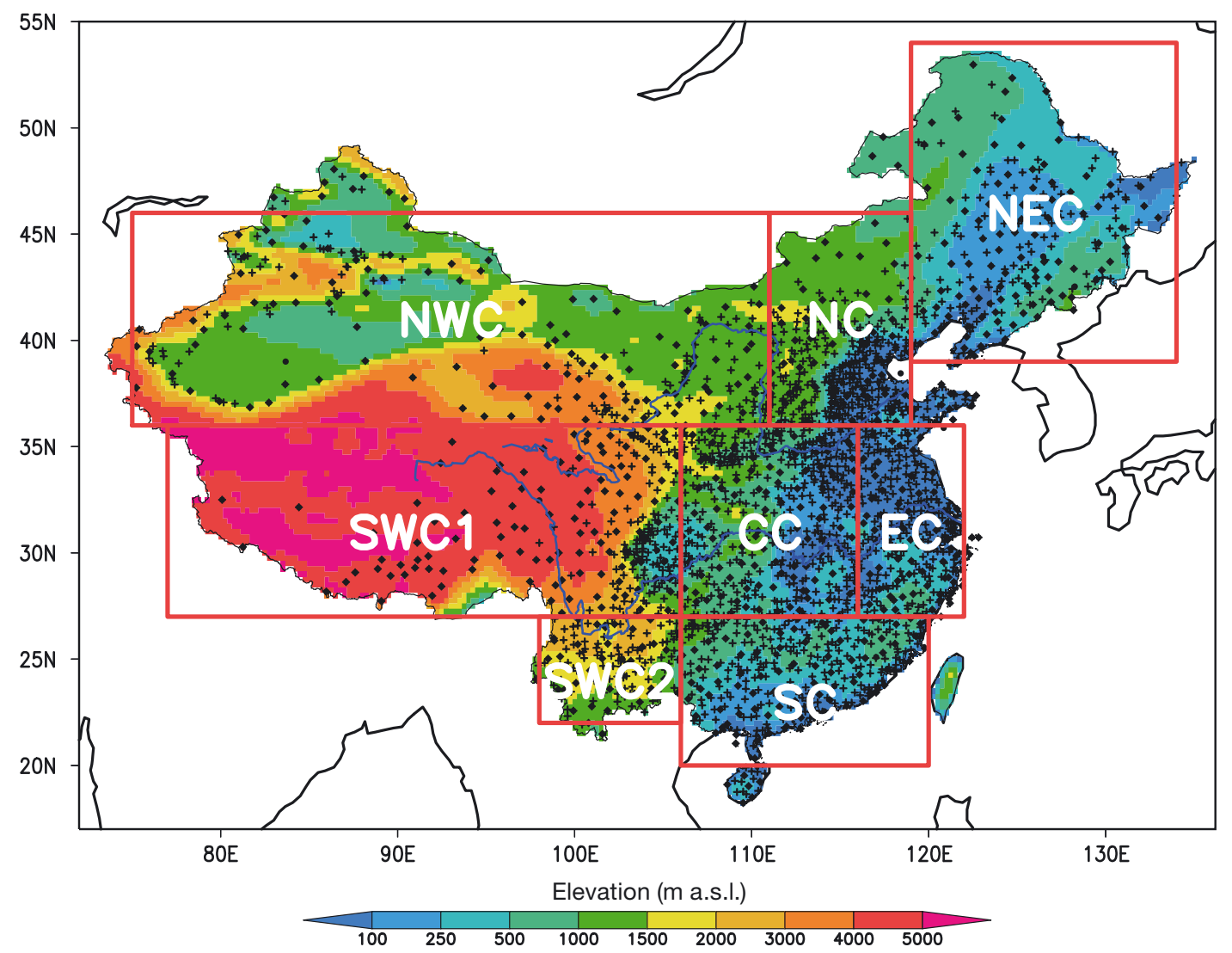

Fig. 1. Topography of China showing the spatial distribution of 2416 observation stations (dots: major stations; crosses: other stations). Red rectangles identify the 8 sub-regions used in this study: NEC, northeastern China; NC, north China; EC, eastern China; CC, central China; SC, southern China; SWC1 and SWC2, southwestern China; NWC, northwestern China 
analysis, we masked them to the same space-time coverage as the observations. Signals were estimated as multiple model ensemble means by first computing individual model ensemble means and then averaging the utilized models. These included signals for the effects of ANT and NAT and their combined effects, as well GHG, AA, and LU.

Many different methods have been employed to estimate the climate response to anthropogenic forcing. One method is to compute multi-model ensemble means for simulations under ANT forcing. The resulting signal is referred to as ANT1. Another method is to use the difference between the ALL and NAT signals (i.e. ANT = ALL - NAT). The resulting signal is referred to as ANT2. The third method is to accumulate responses from individual anthropogenic forcings, including GHG, AA, and LU. The resulting signal is referred to as ANT3. Note that the latter 2 estimates assume that climate response to various forcing agents may be additive (e.g. Cubasch et al. 2001, Meehl et al. 2004). This assumption has been validated for temperature at the global scale (Meehl et al. 2004), although it has not been examined over China. Each method has its own advantages and disadvantages. In this paper, we only used the ANT1 (multi-model ensemble mean under ANT forcing) as the estimate for the anthropogenic forcing signal (hereinafter referred to as 'ANT').

Model data were further processed to produce data for noise estimation as detailed below. In order to make the best use of the available data, we included inter-ensemble differences when estimating covariance structure. This was done by dividing model simulations under different external forcings into 2 chunks: for 1961-2005 and 1901-1945. Respective ensemble means were then removed. To make the noise data comparable with observational coverage, simulations for 1901-1945 were masked with the observational data for 1961-2005, with the year 1961 in the observation matching the year 1901 in the simulation. Secondly, we divided the 13008 yr CTL from the 20 models into non-overlapping, 45 yr chunks and obtained 2 independent samples, each having 130 chunks of data. These 130 chunks of data, along with those from different forcing runs (including 118 of the 45 yr chunks from ALL simulations, 42 from NAT, 48 from GHG, 40 from ANT, 15 from LU, and 33 from AA), made up 2 sets of $42645-\mathrm{yr}$ model output chunks, plus the preindustrial CTL, which are available for the estimation of natural variability (noise1 and noise2). The 45 yr chunks of noise data were split into 2 independent sets, with one set used for optimization and the other for testing.

\section{RESULTS}

\subsection{Observations and simulations}

Fig. 2 shows linear trends in annual mean temperatures for the observed trend as well as for model simulated temperature responses to different forcings. An increase in the observed mean temperature occurred almost everywhere in China. Increases in northeastern and western China were much stronger than in other regions. Some cooling trends occurred in the Sichuan Basin area (Fig. 2a). These findings are consistent with results reported in previous studies (e.g. Ren et al. 2012). Mean temperature responses to ALL, GHG, ANT, and NAT were characterized by warming trends. NAT (Fig. 2c) showed the weakest trend; GHG (Fig. 2d) exhibited the strongest trend. ALL (Fig. 2b) and ANT (Fig. 2g) trends were of similar magnitudes, which were generally weaker than the observed trend. In general, the response to LU forcing (Fig. 2e) exhibited a negative trend, with a similar negative trend appearing in most areas of China, especially on the Tibetan Plateau.

Fig. 3 displays a time series of annual mean temperatures averaged over China, expressed as temperature anomalies relative to the 1961-1990 mean for both observations and model simulations. Visual inspection suggests a good match in the long-term changes in annual mean temperature between the observed trend and the responses to ALL, or between observations and responses to GHG. However, the observed trend was clearly above the upper range of model simulated responses to NAT. Additionally, model simulated responses to LU and AA showed negative trends. Clearly, the observed temperature changes can be explained by a response to ALL or GHG forcings, but not by NAT, LU or AA alone. Linear trends in the observations and in multi-model ensemble means for different forcings are provided in Table 2. The results indicate that trends of ALL, GHG, ANT were close to that of the observed trend (especially for GHG), while the trend of NAT was very weak, and the trend of LU and AA was negative.

\subsection{One-signal analyses}

Fig. 4a shows the best estimates of scaling factors and their $90 \%$ confidence intervals for ALL, GHG, ANT, NAT, and LU based on 1-signal optimal analyses for the annual mean temperature. The detection results are not sensitive to the number of EOFs retained. The ALL, GHG and ANT signals were ro- 

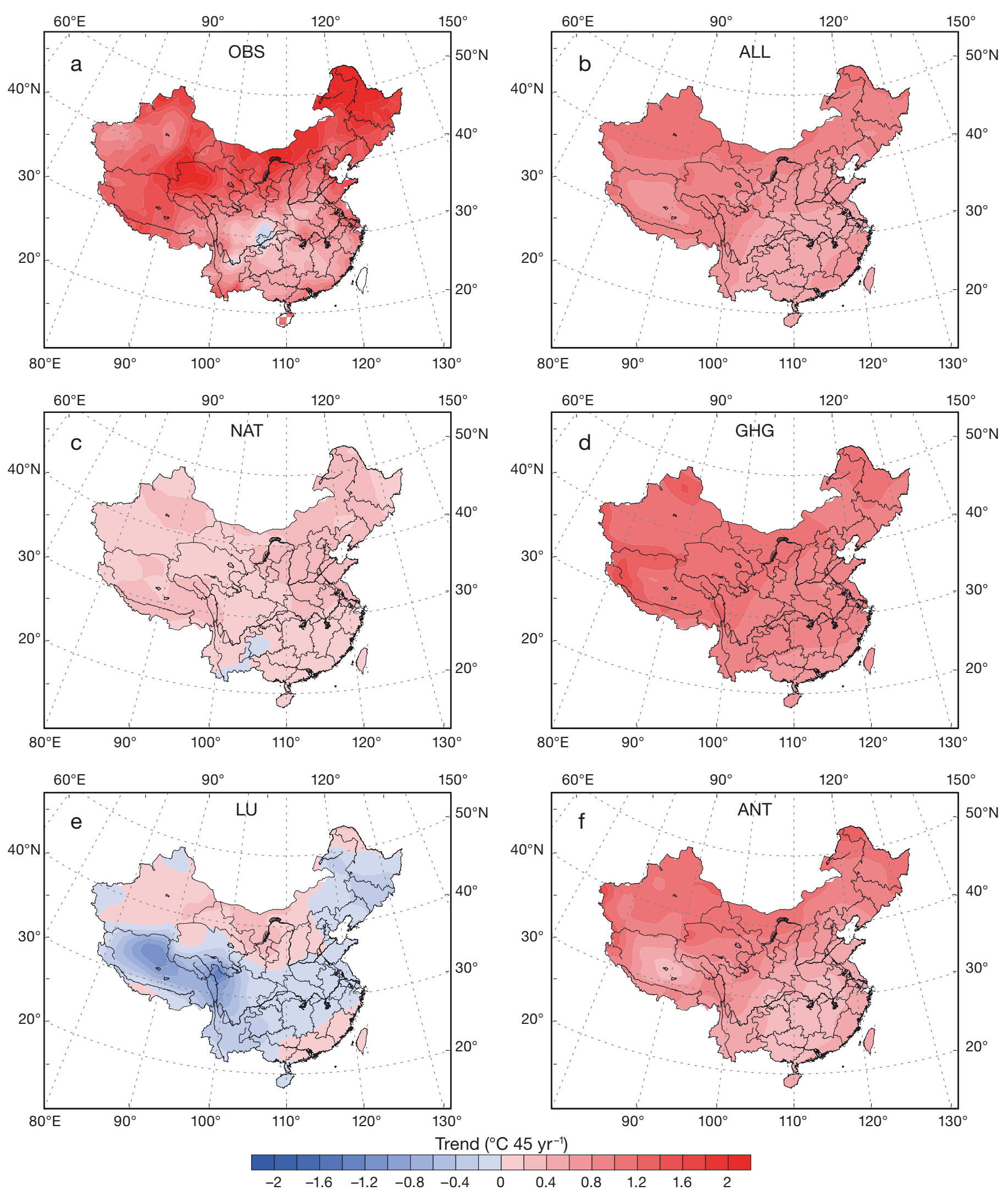

Fig. 2. Estimated trend of annual mean temperatures $\left({ }^{\circ} \mathrm{C}\right.$ change over $\left.45 \mathrm{yr}\right)$ over China under different forcings during the period 1961-2005. OBS: observed trend; ALL: includes anthropogenic and natural external forcings; NAT: includes only solar irradiance and volcanic activity; GHG: greenhouse gases; LU: land use change; ANT: anthropogenic influences 


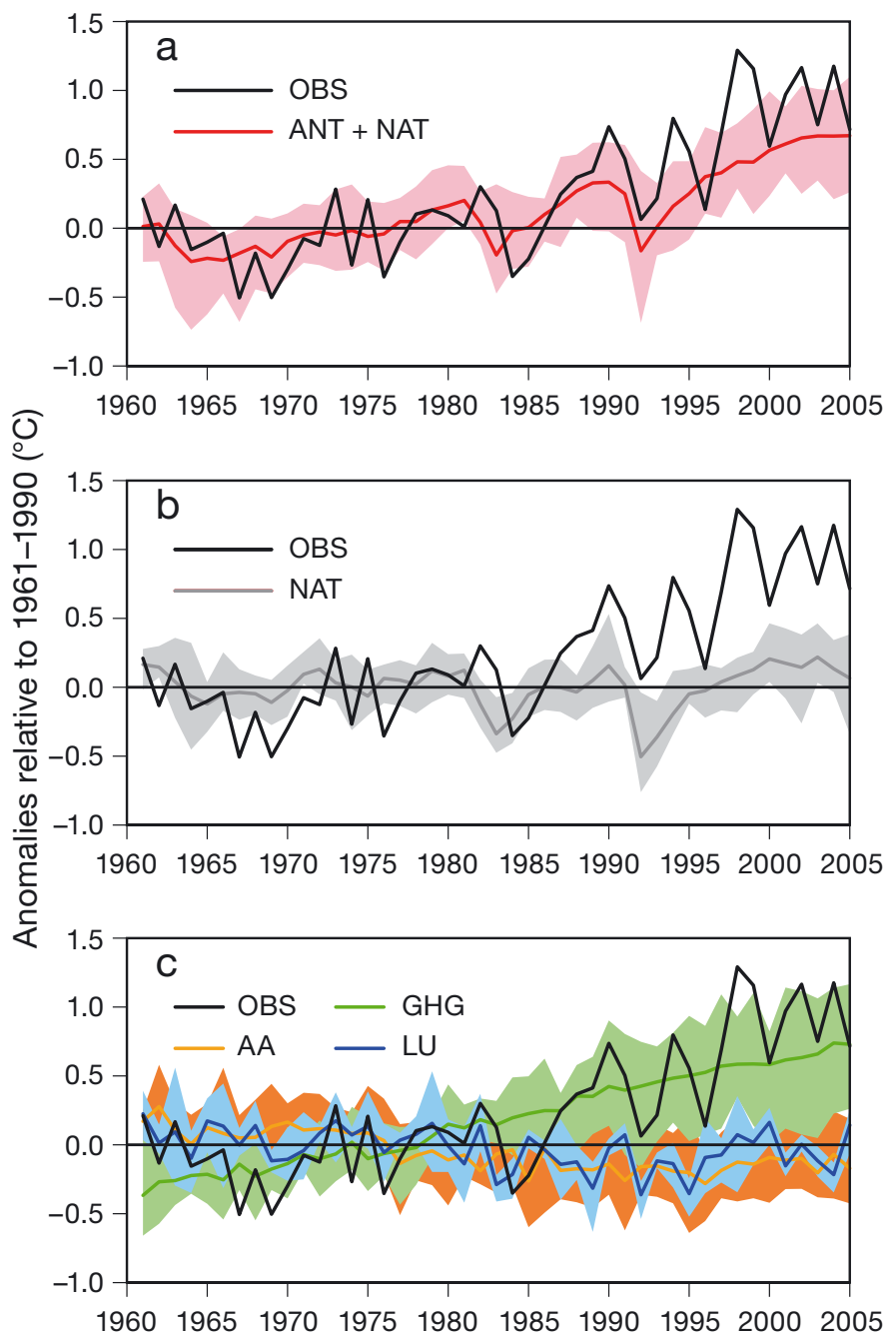

Fig. 3. Annual mean temperature anomalies averaged across China from observation and model simulations during the period of 1961-2005. Shaded bands: multi-model range. OBS: observed trend; ANT: anthropogenic influences; NAT: includes only solar irradiance and volcanic activity; GHG: greenhouse gases; AA: anthropogenic aerosols; LU: land use change

Table 2. Observed and model simulated trends $\left({ }^{\circ} \mathrm{C}\right.$ change over $10 \mathrm{yr}$ ) of annual mean temperature over China. See Fig. 2 for abbreviations

\begin{tabular}{|ccccccc|}
\hline OBS & ALL & GHG & NAT & LU & AA & ANT \\
\hline 0.28 & 0.18 & 0.25 & 0.09 & -0.04 & -0.08 & 0.17 \\
\hline
\end{tabular}

bustly detected in annual mean temperature individually across a wide range of EOF truncations as their scaling factors were significantly greater than zero. Results shown in Fig. 4a are based on 40 EOFs 'full rank', which passed a residual consistency test. Model simulated responses to the effect of combined anthropogenic and natural forcing were smaller (though not significantly) than the observed change. The NAT-only and LU signals were not detected in the observation. This suggests that GHG, or ANT including GHG, or ALL including ANT alone can explain observed temperature changes, but NAT forcing or LU forcing alone cannot. Changes in land cover can have substantial impacts on extreme temperatures due to land-atmosphere interactions (Seneviratne et al. 2006). Christidis et al. (2013) showed that land use changes may have a cooling effect on temperature extremes at a global scale (especially on extremely warm days) due to the increase of albedo accompanied with deforestation. Wen et al. (2013) also found a detectable effect of LU on annual maximum daily temperatures, suggesting that the impact of land use changes on extremely warm days might be detectable even at a regional scale. However, the LU effect is hard to detect in annual mean temperature changes on a global scale (Christidis et al. 2013). Although there is a cooling effect of the mean temperature response to LU over China as simulated by multi-models (Fig. 2e), the signal was not detectable in our research. Consequently, we conclude that LU is not a dominant forcing.

\subsection{Two-signal analyses}

A 2-signal analysis was also carried out with different combinations of forcing responses, including ANT (individual anthropogenic forcing) and NAT (only natural forcing), GHG (only GHG) and other anthropogenic forcing (ANT-GHG, including anthropogenic aerosols and land use), LU and other anthropogenic forcing (ANT-LU, representing GHG and anthropogenic aerosols). These analyses shed more light on the relative importance of individual forcing.

Fig. 5 displays $90 \%$ confidence regions and marginal confidence intervals for the 2-signal detection analysis using ANT and NAT. The origin $(0,0)$ is outside the $90 \%$ confidence region, suggesting that ANT and NAT are jointly detected at the $90 \%$ confidence level. The marginal $90 \%$ confidence intervals for ANT are above 0, but for NAT, include 0. This suggests that ANT is clearly detected in the annual mean temperature but NAT is not. It also indicates that the effects of ANT on annual mean temperatures can be separated from NAT.

The magnitude of scaling factors and their $90 \%$ marginal confidence intervals for ANT are also comparable to those from the 1-signal analysis. The 2signal analysis results are also very robust to differ- 

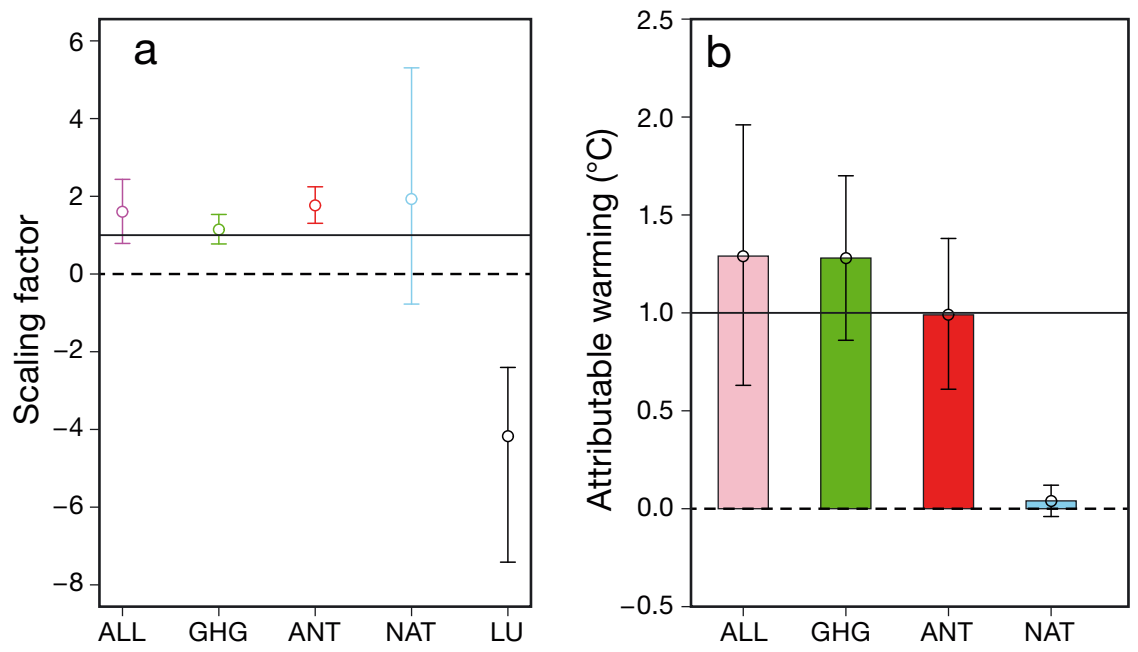

Fig. 4. (a) Scaling factors and their 5-95\% uncertainty ranges for anthropogenic and natural external forcings (ALL); greenhouse gases (GHG); anthropogenic influences (ANT); solar irradiance and volcanic activity (NAT); and land use changes (LU) from 1-signal; (b) attributable warming and their 5-95\% uncertainty ranges from 1-signal (ALL and GHG) and 2-signal analysis (ANT and NAT)
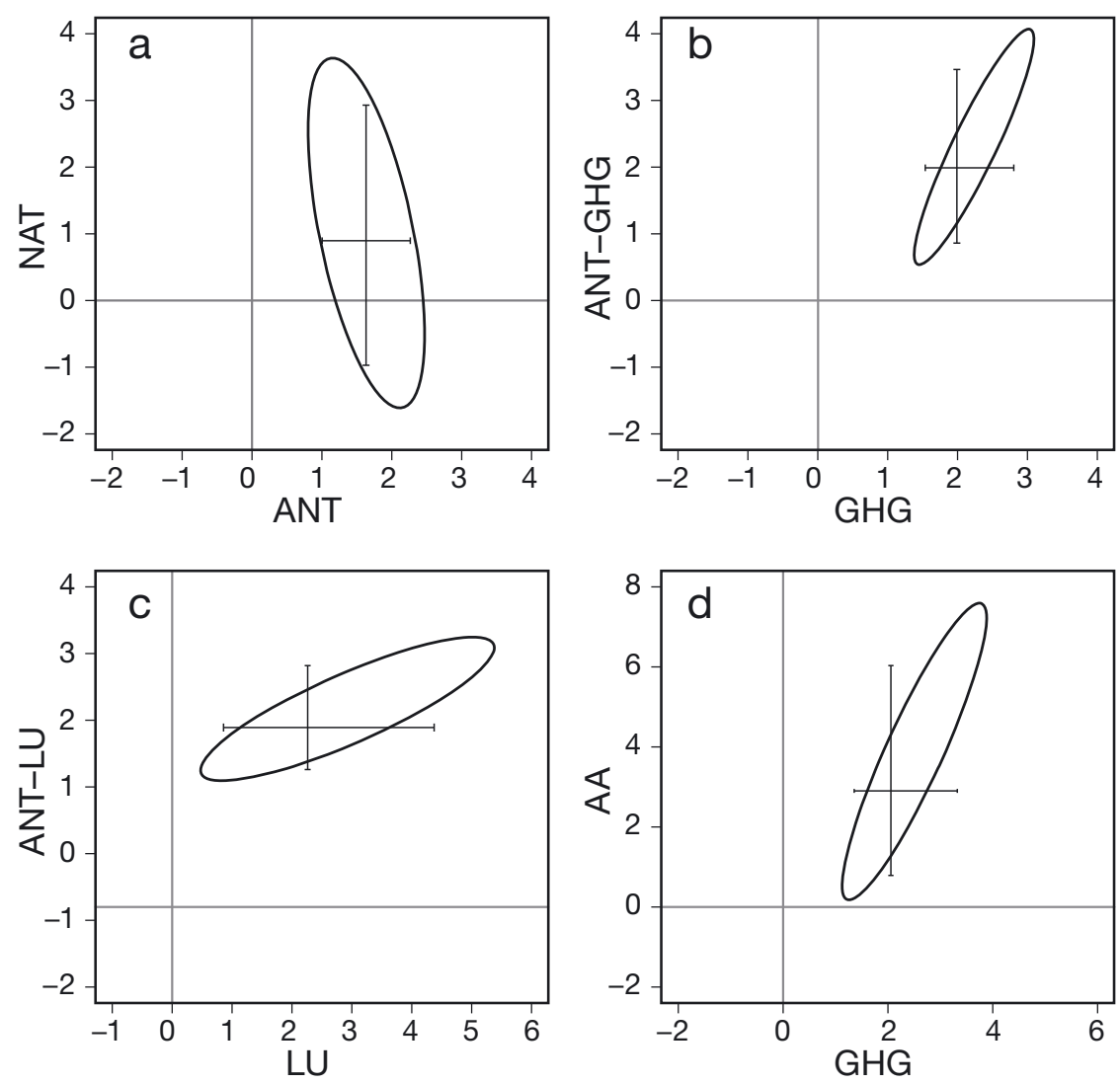

Fig. 5. Scaling factors, their $90 \%$ joint confidence regions (bars), and marginal $90 \%$ confidence intervals (ellipses) obtained from 2-signal analyses of (a) anthropogenic (ANT) and natural (NAT) forcings, (b) greenhouse gas emissions (GHG) and the combination of ANT-GHG, (c) land use (LU) and the combination of ANT-LU, and (d) GHG and anthropogenic aerosols (AA) ent EOF truncations. ALL and ANT were clearly detectable but NAT was clearly not detectable in the 1-signal analyses. That ANT and NAT can be jointly detected, and the effects of ANT can be separated from those of NAT in the 2-signal analyses suggests that only anthropogenic forcing can explain the observed annual mean temperature changes in China from 1961 to 2005.

A 2-signal analysis conducted on a combination of individual anthropogenic forcings suggests that the effect of GHG could be separated from those of other anthropogenic forcings for annual mean temperature. Analysis for annual mean temperature conducted with GHG against ANT-GHG (Fig. 5b) suggests that the effect of GHG could be separated from the combined effect of anthropogenic aerosols and land use changes. The uncertainty range of the ANT-GHG scaling factor was much larger than that for GHG. A comparison of LU against ANT-LU (Fig. 5c) suggests that the effect of land use change could be separated from the combined effect of GHG and anthropogenic aerosol, but the effect of LU was not detected in the 1-signal analysis.

The 2-signal analysis for AA and GHG indicates that the effect of GHG can be separated from that of $\mathrm{AA}$, and that the separate detection of AA from GHG is very robust (Fig. 5d). Analysis for GHG and LU failed to separate the GHG contribution from that of LU, suggesting that simulated responses to GHG and LU may be highly correlated (not shown).

Fig. 4b shows the attributable warming of different forcings from 1and 2-signal detection. Attributable warming was estimated as the linear least-square trend of the relevant time series multiplied by the corresponding scaling factors. From the 1signal detection results, the attributable warming of ALL and GHG to the mean temperature of the observed 
trend was $1.29^{\circ} \mathrm{C}\left(90 \% \mathrm{CI} 0.63 \sim 1.96^{\circ} \mathrm{C}\right)$ and $1.28^{\circ} \mathrm{C}$ $\left(90 \%\right.$ CI $0.86 \sim 1.70^{\circ} \mathrm{C}$ ), respectively (Fig. $\left.4 \mathrm{~b}\right)$. The warming attributable to ANT was $0.99^{\circ} \mathrm{C}(90 \% \mathrm{CI}$ $0.61 \sim 1.38^{\circ} \mathrm{C}$ ), while the contribution of NAT was $0.04{ }^{\circ} \mathrm{C}\left(90 \% \mathrm{CI}-0.04 \sim 0.12^{\circ} \mathrm{C}\right)$ from the 2-signal analysis (Fig. 4b).

\section{DISCUSSION AND CONCLUSIONS}

Using an optimal detection technique and CMIP5 multi-model simulations, we have shown that the effect of anthropogenic forcing on climate change is detectable in China. The combined effect of greenhouse gas emissions and sulfate aerosol forcing is clearly detectable in the observed annual mean temperature change over China from 1961-2005. The effects of ANT and NAT are separately detectable, and the effect of GHG can be separated from other anthropogenic forcings for annual mean temperature. The effect of LU failed to separate. The climate response to greenhouse gas forcing can be clearly and robustly identified in the annual mean temperature, and results show that only anthropogenic forcing can explain the observed changes in China's mean temperature from 1961 to 2005.

Our detection results were based on the most stateof-the-art multiple CMIP5 models. Our results are consistent with, and further confirm the findings of Stott (2003) — who used the single Hadley Centre Coupled Model (HadCM3), and of Zhang et al. (2006), who used 2 versions of 2 general circulation models (GCMs) - that the anthropogenic influence on warming can be detected in Asia.

In this study, the effect of LU was not detected. But the influence of LU at the regional and local scales is likely not negligible, and should not be discounted, in particular over China with its long history of agricultural activities and its high population (e.g. Gao et al. 2007). Perhaps the global LU forcing data used in our simulation did not fully reflect Chinese LU changes, due to a lack of sufficient local or regional details. Future regional climate detection studies, employing the LU and aerosol datasets developed in China based on both satellite and field based studies (e.g. Liu et al. 2003, Zhang et al. 2012, 2013) are needed in order to increase our knowledge and to better understand the attribution of observed climate change in this region.

Acknowledgements. We acknowledge the World Climate Research Program's Working Group on Coupled Modeling, which is responsible for CMIP, and thank climate modeling groups for producing and making model output available. For CMIP, the US Department of Energy's Program for Climate Model Diagnosis and Intercomparison provided coordinating support and led the development of software infrastructure in partnership with the Global Organization for Earth System Science Portals. This research is a contribution to a collaborative project of the Joint Working Group XIII between the Meteorological Service of Canada and the China Meteorological Administration. We are grateful to X. Zhang, H. Wan and Q. H. Wen of Environment Canada for their support and assistance in this research. We are grateful to Dr. Y. X. Zhang for assistance with English. This research received support from R\&D Special Fund for Public Welfare Industry (meteorology) (GYHY201306019), National Natural Science Foundation of China (41275078), Grant Projects of China Clean Development Mechanism Fund (121312), and Climate Change Foundation of China Meteorological Administration (CCSF201339).

\section{LITERATURE CITED}

Allen MR, Stott PA (2003) Estimating signal amplitudes in optimal fingerprinting. I. Theory. Clim Dyn 21:477-491

Allen MR, Tett SFB (1999) Checking for model consistency in optimal fingerprinting. Clim Dyn 15:419-434

Bindoff NL, Stott PA, AchutaRao KM, Allen MR and others (2013) Detection and attribution of climate change: from global to regional. In: Stocker TF, Qin D, Plattner GK, Tignor $M$ and others (eds) Climate change 2013: the physical science basis. Contribution of Working Group I to the 5th Assessment Report of the Intergovernmental Panel on Climate Change. Cambridge University Press, Cambridge, p 867-952

CCNARCC (Committee for China's National Assessment Report on Climate Change) (2007) China's national assessment report on climate change. Science Press, Beijing (in Chinese)

Christidis N, Stott PA, Hegerl GC, Betts R (2013) The role of land use change in the recent warming of daily extreme temperatures. Geophys Res Lett 40:589-594

Cubasch U, Meehl GA, Boer GJ, Stouffer RJ and others (2001) Projections of future climate change. In: Houghton JH, Ding Y, Griggs DJ, Noguer M and others (eds) Climate change 2001: the scientific basis. Contribution of Working Group I to the 3rd Assessment Report of the Intergovernmental Panel on Climate Change. Cambridge University Press, Cambridge, p 525-582

Gao XJ, Zhang DF, Chen ZX, Pal JS, Giorgi F (2007) Land use effects on climate in China as simulated by a regional climate model. Sci China Earth Sci 50:620-628

Gao XJ, Shi Y, Giorgi F (2011) A high resolution simulation of climate change over China. Sci China Earth Sci 54: 462-472

Gareth SJ, Stott PA, Christidis N (2013) Attribution of observed historical near-surface temperature variations to anthropogenic and natural causes using CMIP5 simulations. J Geophys Res 118:4001-4024

Guo DL, Wang HJ (2013) Simulation of permafrost and seasonally frozen ground conditions on the Tibetan Plateau, 1981-2010. J Geophys Res Atmos 118:5216-5230

Hegerl GC, Zwiers FW, Braconnot P, Gillett NP and others (2007) Understanding and attributing climate change. In: Solomon S, Qin D, Manning M, Chen Z and others (eds) Climate change 2007: the physical science basis. Contri- 
bution of Working Group I to the 4th Assessment Report of the Intergovernmental Panel on Climate Change. Cambridge University Press, Cambridge, p 665-745

Hegerl GC, Zwiers F (2011) Use of models in detection and attribution of climate change. WIREs Clim Change 2: 570-591

IPCC (2007) Climate change 2007: the physical science basis. In: Solomon S, Qin D, Manning M, Chen Z and others (eds) Contribution of Working Group I to the 4th Assessment Report of the Intergovernmental Panel on Climate Change. Cambridge University Press, Cambridge

IPCC (2013) Climate change 2013: the physical science basis. In: Stocker TF, Qin D, Plattner GK, Tignor M and others (eds) Contribution of Working Group I to the 5th Assessment Report of the Intergovernmental Panel on Climate Change. Cambridge University Press, Cambridge

Li Z, Yan ZW, Wu HY (2015) Updated homogenized Chinese temperature series with physical consistency. Atmos Ocean Sci Lett 8:17-22

Liu JY, Liu ML, Zhuang DF, Zhang ZX, Deng XZ (2003) Study on spatial pattern of land-use change in China during 1995-2000. Sci China Earth Sci 46:373-384

Meehl GA, Washington WM, Amman C, Arblaster JM, Wigley TML, Tebaldi C (2004) Combinations of natural and anthropogenic forcings and 20th century climate. J Clim 17:3721-3727

Ming Y, Ramaswamy V (2009) Nonlinear climate and hydrological responses to aerosol effect. J Clim 22:1329-1339

Qian C, Fu CB, Wu ZH (2011) Changes in the amplitude of the temperature annual cycle in China and their implication for climate change research. J Clim 24:5292-5302

Ren GY, Zhou YQ (2014) Urbanization effect on trends of extreme temperature indices of national stations over Mainland China, 1961-2008. J Clim 27:2340-2360

Ren GY, Ding YH, Zhao ZC, Zheng JW, Wu TW, Tang GL, $\mathrm{Xu} Y$ (2012) Recent progress in studies of climate change in China. Adv Atmos Sci 29:958-977

Seneviratne SI, Luthi D, Litschi M, Schar C (2006) Land atmosphere coupling and climate change in Europe. Nature 443:205-209

Stott PA (2003) Attribution of regional-scale temperature changes to anthropogenic and natural causes. Geophys Res Lett 30:1728, doi:10.1029/2003GL017324

Stott PA, Jones GS (2012) Observed $21^{\text {st }}$ century temperatures further constrain likely rates of future warming. Atmos Sci Lett 13:151-156

Stott PA, Gillett NP, Hegerl GC, Karoly DJ, Stone DA, Zhang XB, Zwiers F (2010) Detection and attribution of climate change: a regional perspective. WIREs Clim Chang 1: 192-211

Sui Y, Lang XM, Jiang DB (2014) Time of emergence of climate signals over China under the RCP4.5 scenario. Clim Change 125:265-276

Sun Y, Zhang XB, Zwiers FW, Song L and others (2014) Rapid increase in the risk of extreme summer heat in Eastern China. Nat Clim Change 4:1082-1085

Tang GL, Ren GY (2005) Reanalysis of surface air tempera-

Editorial responsibility: Gouyu Ren,

Beijing, China ture change of the last 100 years over China. Clim Environ Res 10:791-798 (in Chinese)

Taylor KE, Stouffer RJ, Meehl GA (2012) An overview of CMIP5 and the experiment design. Bull Am Meteorol Soc 93:485-498

Wang XL, Wen QH, Wu Y (2007) Penalized maximal $t$ test for detecting undocumented mean change in climate data series. J Appl Meteorol Climatol 46:916-931

Wang T, Wang HJ, Otter OH, Gao YQ, Suo LL, Furevik T, Yu L (2013) Anthropogenic forcing of shift in precipitation in Eastern China in late 1970s. Atmos Chem Phys Discuss 13:11997-12032

Wen HQZ, Zhang XB, Xu Y, Wang B (2013) Detecting human influence on extreme temperatures in China. Geophys Res Lett 40:1171-1176

Wu J, Gao XJ (2013) A gridded daily observation dataset over China region and comparison with the other datasets. Chin J Geophys 56:1102-1111 (in Chinese with English abstract)

> Wu J, Gao XJ, Giorgi F, Chen ZhH, Yu DF (2012) Climate effects of the Three Gorges Reservoir as simulated by a high resolution double nested regional climate model. Quart Int 282:27-36

Xu Y, Gao XJ, Shen Y, Xu CH, Shi Y, Giorgi F (2009) A daily temperature dataset over China and its application in validating a RCM simulation. Adv Atmos Sci 26: 763-772

Zhai P, Pan X (2003) Trends in temperature extremes during 1951-1999 in China. Geophys Res Lett 30:1913, doi: 10.1029/2003GL018004

Zhang XB, Zwiers FW, Stott PA (2006) Multimodel multisignal climate change detection at regional scale. J Clim 19: 4294-4307

Zhang XY, Wang YQ, Niu T, Zhang XC, Gong SL, Zhang YM, Sun JY (2012) Atmospheric aerosol compositions in China: spatial/temporal variability, chemical signature, regional haze distribution and comparisons with global aerosols. Atmos Chem Phys 12:779-799

Zhang XY, Sun JY, Wang YQ, Li WJ and others (2013) Factors contributing to haze and fog in China. Chin Sci Bull 58:1178-1187 (in Chinese)

Zhang DF, Gao XJ, Luo Y, Xia J, Giorgi F (2015) The attribution of anthropogenic forcings and natural variability on the observed climate change over China and its main river basins as simulated by RegCM4.0. Chin Sci Bull (in press)

Zhou TJ, Yu RC (2006) Twentieth century surface air temperature over China and the globe simulated by coupled climate models. J Clim 19:5843-5858

Zhou TJ, Ma SM, Zou LW (2014) Understanding a hot summer in central eastern China: summer 2013 in context of multi-model trend analysis. In: Herring SC, Hoerling MP, Peterson TC, Stott PA (eds) Explaining extreme events of 2013 from a climate perspective. Bull Am Meteorol Soc (Spec Suppl) 95:S54-S57

> Zwiers FW, Zhang XB (2003) Toward regional-scale climate change detection. J Clim 16:793-797

Submitted: October 24, 2014; Accepted: December 29, 2014 Proofs received from author(s): March 31, 2015 